\title{
Inhibition of angiotensin converting enzyme cannot prevent increases in angiotensin II production in coronary circulation
}

\author{
Y Hojo, U Ikeda, T Katsuki, O Mizuno, H Fujikawa, K Shimada
}

\begin{abstract}
Objective-To determine whether inhibition of angiotensin converting enzyme (ACE) can prevent angiotensin II production in the coronary circulation induced by percutaneous transluminal coronary angioplasty (PTCA) in patients with myocardial ischaemia.

Design, patients-41 patients who underwent elective PTCA and six control subjects who received diagnostic coronary angiography were studied. Patients were divided into two groups according to the chronic administration of ACE inhibitors (group A, 15 patients treated with ACE inhibitors; group B, 26 patients without ACE inhibitors). Blood samples were drawn through catheters placed in the aorta and coronary sinus before and 24 hours after PTCA.

Results-Mean levels of ACE activity in the aorta were significantly lower in patients in group A than in group B. However, mean angiotensin II concentrations in the aorta were not significantly different between the two groups. Differences in basal angiotensin II concentrations between the coronary sinus and aorta, which reflected basal angiotensin II production in the coronary circulation, were not significant among group A, group B, and control subjects. The production of angiotensin II in the coronary circulation was significantly increased 24 hours after PTCA in both group A and group B to the same extent. No significant changes were observed in control subjects 24 hours after diagnostic coronary angiography.

Conclusions-This study revealed that inhibition of ACE activity by ACE inhibitors could not prevent increases in angiotensin II production in the coronary circulation induced by PTCA. (Heart 2000;83:574-576)
\end{abstract}

Keywords: angiotensin converting enzyme; chymase; angioplasty

Although percutaneous transluminal coronary angioplasty (PTCA) is used as an effective therapeutic method in patients with obstructive coronary artery disease, several problems still limit clinical outcome. Acute occlusion of coronary arteries occurs during PTCA with an incidence of $2-11 \% .{ }^{1}$ Activation of coagulation and coronary vasospasm is speculated to be related to acute occlusion of coronary arteries during PTCA. ${ }^{2} 3$ Late restenosis of PTCA sites occurs with an incidence of $20-40 \%$, limiting the long term efficacy of the procedure..$^{4-8}$ Currently, various substances including vasoactive peptides, products of coagulation, cytokines, and growth factors are believed to be involved in acute thrombosis and late restenosis in PTCA by establishing a positive autocrine and paracrine feedback loop "cascade mechanism". ${ }^{9}$ In this process, angiotensin II might contribute to sustained vascular contraction and proliferation of vascular smooth muscle cells.

Administration of angiotensin converting enzyme (ACE) inhibitors has been reported to prevent restenosis of balloon injured arteries in rats. However, clinical application of ACE inhibitors did not prevent restenosis after coronary intervention. ${ }^{10}$ Previous studies have indicated that plasma angiotensin II concentrations return to baseline levels during chronic administration of ACE inhibitors, ${ }^{11}$ and that exercise induced rise in angiotensin II concentrations measured in the veins draining the human leg could not be prevented by captopril. ${ }^{12} 13$ These phenomena are explained by the existence of another angiotensin II forming enzyme, chymase, which is not inhibited by ACE inhibitors in humans.

We investigated whether ACE inhibition using ACE inhibitors can prevent angiotensin II production in the coronary circulation induced by PTCA.

\section{Methods}

PATIENTS

We studied 41 patients (34 men and seven women, mean age 61.6 (9.9) years, range 36-77 years) with documented myocardial ischaemia who underwent elective PTCA. The angioplasty was performed on isolated significant stenotic lesions of left coronary arteries (34 left anterior descending arteries, six left circumflex arteries, and one protected left main trunk lesion). Eleven patients received plain old balloon coronary angioplasty (POBA), 14 received percutaneous transluminal coronary rotational atherectomy (PTRA), and 16 received coronary stent implantation.

All patients received $81 \mathrm{mg}$ of aspirin, calcium channel blockers (40 $\mathrm{mg}$ of nifedipine or $90 \mathrm{mg}$ of diltiazem), and $40 \mathrm{mg}$ of isosorbide dinitrate before PTCA. Patients expected to undergo coronary stent implantation also received $200 \mathrm{mg}$ of ticlopidine. Patients were divided into two groups according to the chronic administration of ACE (group A, 15 patients treated with ACE inhibitors; group B, 26 patients without ACE inhibitors). In group 
A, 13 patients had received enalapril $(5 \mathrm{mg} /$ day) and two had received captopril $(37.5 \mathrm{mg} /$ day). Six control subjects without coronary artery stenosis who underwent diagnostic coronary angiography were examined as controls. All patients gave their informed consent to participate in the study.

ANGIOPLASTY PROCEDURE

We cannulated the patients' femoral arteries with a 7 French sheath and femoral veins with a 6 French sheath under local anaesthesia with $1 \%$ lidocaine hydrochloride. Selective coronary angiography was performed and the most accurate evaluation of the stenotic lesion was determined. A non-ionic contrast media (ioxaglate) was used for all patients. Heparin (5000 units) was administered intravenously before PTCA and continued for 24 hours after PTCA to increase the activated partial thromboplastin time by 1.5 to 2 -fold over normal control values. A 0.014 inch guidewire was used in POBA and stent implantation, and a 0.009 inch guidewire was used in PTRA to cross the stenotic coronary lesion. PTCA was performed using a monorail balloon catheter system. The number of inflations, the inflation pressure, and indication for PTRA were decided by the operator. In stent implantation, one stent was implanted in each patient and was sufficient to cover the stenotic lesions.

\section{BLOOD COLLECTION}

A 5 French catheter was inserted from the femoral venous sheath and placed in the coronary sinus for 24 hours. Venous blood samples were obtained through the catheter from the coronary sinus before and 24 hours after angioplasty or diagnostic coronary angiography. After the initial $3 \mathrm{ml}$ of blood was discarded, blood samples were gently obtained using syringes. Blood samples not obtained smoothly were discarded. We also took blood samples from the femoral artery before and 24 hours after PTCA in eight patients.

MEASUREMENT OF ACE ACTIVITY AND

ANGIOTENSIN II CONCENTRATIONS

Activity of ACE was measured by colorimetry with a commercially available kit (Fujirebio Inc, Tokyo, Japan). The results are expressed in international units per litre. The normal range of serum ACE in our laboratory is 8.321.4 IU/1. Concentrations of angiotensin II were determined by radioimmunoassay using a specific anti-angiotensin II antibody (SRL Inc, Tokyo, Japan). Cross reactivity of the antibody with angiotensin I was $0.037 \%$. The sensitivity of the radioimmunoassay for angiotensin II was $1.25 \mathrm{pg} / \mathrm{ml}$. The normal range of serum angiotensin II concentrations is $<22 \mathrm{pg} / \mathrm{ml}$.

STATISTICAL ANALYSIS

Data are expressed as mean (SEM). Comparisons were performed by unpaired Student's $t$ test or analysis of variance (ANOVA). Values of $\mathrm{p}<0.05$ were considered significant.

\section{Results}

Successful coronary dilatation was achieved in all patients (from $0.53(0.09) \mathrm{mm}$ to 2.87

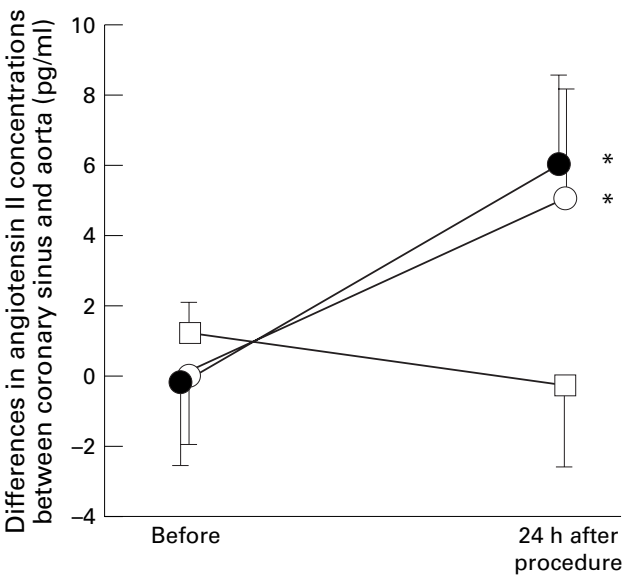

Figure 1 Differences in angiotensin II concentrations between the coronary sinus and aorta, which reflect production of angiotensin II in the coronary circulation, increased significantly 24 hours after PTCA to the same degree in patients treated with (closed circles) and without (open circles) ACE inhibitors. No significant changes were observed in control subjects 24 hours after diagnostic coronary angiography (open squares). Data expressed as mean (SEM). ${ }^{\star} p<0.05$ versus before PTCA.

(0.11) mm, p < 0.0001). No acute coronary occlusion was observed in any of patients.

Mean levels of ACE activity in the aorta were significantly lower in patients in group A (treated with ACE inhibitor) than in group B (without ACE inhibitor) (3.67 (1.10) IU/1 $v$ 8.66 (0.73) IU/1, p < 0.001). However, mean angiotensin II concentrations in the aorta were not significantly different between the two groups (18.4 (2.0) pg/ml v $22.2(2.1) \mathrm{pg} / \mathrm{ml})$.

Angiotensin II concentrations in the coronary sinus were significantly increased 24 hours after PTCA, from 19.8 (1.9) $\mathrm{pg} / \mathrm{ml}$ to 24.8 (2.9) $\mathrm{pg} / \mathrm{ml}$. No significant differences in the increase in angiotensin II concentrations were observed between the devices used for PTCA. No significant changes in angiotensin II concentrations were found in the femoral arterial blood 24 hours after PTCA (from 17.2 (2.0) $\mathrm{pg} / \mathrm{ml}$ to $17.8(1.8) \mathrm{pg} / \mathrm{ml}$ ).

As shown in fig 1, differences in basal angiotensin II concentrations between the coronary sinus and aorta, which reflected basal angiotensin II production in the coronary circulation, were not significantly different among group A, group B, and control subjects. The production of angiotensin II in the coronary circulation increased significantly 24 hours after PTCA both in group A and group B to the same extent (group A, from -0.27 (2.50) pg/ $\mathrm{ml}$ to $6.00(2.46) \mathrm{pg} / \mathrm{ml}, \mathrm{p}<0.01$; group $\mathrm{B}$, from -0.08 (2.08) $\mathrm{pg} / \mathrm{ml}$ to 4.96 (3.11) $\mathrm{pg} / \mathrm{ml}$, $\mathrm{p}<0.05$, respectively). No significant changes were observed in control subjects $24 \mathrm{~h}$ after diagnostic coronary angiography.

\section{Discussion}

We found increases in angiotensin II concentrations in the coronary sinus after PTCA. No significant increases in angiotensin II concentrations were observed in the femoral arterial blood, suggesting that the changes were only induced in the coronary vascular bed. The increased angiotensin II concentrations may indicate de novo synthesis and secretion of 
angiotensin II as an inflammatory response after PTCA. This procedure has been suggested to produce acute local thrombosis and mechanical injury, triggering cytokine/growth factor expression by resident macrophages and smooth muscles. ${ }^{9}$ These substances might induce increases in angiotensin II expression in injured vessels.

It is likely that the increases in angiotensin II production in the coronary circulation contribute to sustained vascular contraction. Angiotensin II is also a potent mitogenic and hypertrophic factor for vascular smooth muscle cells. ${ }^{14-17}$ Weber and colleagues ${ }^{18}$ reported that increases in DNA synthesis induced by angiotensin II were observed even 48 hours after exposure of rat aortic smooth muscle cells. Thus, increases in angiotensin II concentrations in the coronary vascular bed could contribute to late restenosis of dilated vessels after PTCA.

In the present study, ACE activity was significantly suppressed by ACE inhibitors, while angiotensin II concentrations did not differ between patients with and without ACE inhibitors. One possible explanation for these observations is that ACE inhibitors do not fully inactivate ACE enzyme in all tissues. The other possibility is that another angiotensin II forming enzyme, chymase, contributes to angiotensin II. Previously, Wolny and colleagues ${ }^{19}$ reported that chymase is responsible for the majority of angiotensin II production in human cardiac tissue. Okunishi and colleagues ${ }^{20}$ reported that only $30-40 \%$ of the conversion of angiotensin I to angiotensin II depends on ACE in human arteries, and the remaining angiotensin II formation depends on chymase. In the present study, ACE activity was significantly lower in patients treated with ACE inhibitors than in those without ACE inhibitors, while angiotensin II concentrations in the aorta did not differ between the two groups. This finding is consistent with the previous observation that angiotensin II concentrations return to baseline levels during chronic administration of ACE inhibitors, ${ }^{11}$ probably via a chymase dependent mechanism. Furthermore, we found that inhibition of ACE activity by ACE inhibitors cannot prevent angiotensin II production in the coronary circulation induced by PTCA. It has also been reported that ACE inhibitors reduce restenosis in rodent models of balloon angioplasty but not in larger animals, in which chymase can be shown to be induced after vascular injury. ${ }^{21}{ }^{22}$

These observations might account for the inability of ACE inhibitors to prevent late restenosis after coronary angioplasty in previous clinical trials. If increased angiotensin II production plays an important role in restenosis, angiotensin II receptor antagonists may help to prevent late restenosis after PTCA.

1 Vaitkus PT, Laskey WK. Efficacy of adjunctive thrombolytic therapy in percutaneous transluminal coronary angioplasty. f Am Coll Cardiol 1994;24:1415-23.

2 de Feyter PJ, van den Brand M, Jaarman GJ, et al. Acute coronary artery occlusion during and after percutaneous transluminal coronary angioplasty : frequency, prediction, clinical course, management, and follow-up. Circulation 1991;83:927-36.

3 Fischell TA, Derby G, Tse TM, et al. Coronary vasoconstriction routinely occurs after percutaneous transluminal angioplasty. Circulation 1988;78:1323-34.

4 Bourassa MG. Silent myocardial ischemia after coronary angioplasty; distinguishing the shadow from the substance. f Am Coll Cardiol 1992;19:1410-11.

5 Capron L, Heudes D, Chajara A, et al. Effect of ramipril, an inhibitor of angiotensin converting enzyme, on the response of the rat thoracic aorta to injury with a balloon catheter. F Cardiovasc Pharmacol 1991;18:207-11.

6 Holmes DR, Vlietstra RR, Smith HS, et al. Restenosis after percutaneous transluminal coronary angioplasty: a report from the PTCA registry of the National Heart, Lung, and Blood Institute. Am f Cardiol 1984;53:77C-81C.

7 Nobuyoshi M, Kimura T, Nosaka H, et al. Restenosis after successful percutaneous transluminal coronary angioplasty: serial angiographic follow-up of 229 patients. $\mathcal{F}$ Am Coll Cardiol 1988;12:616-23.

8 Shironati M, Yui Y, Kawai C. Restenosis after coronary angioplasty: pathogenesis of neointimal thickening initiated by endothelial loss. Endothelium 1993;1:5-22.

9 Libby P, Schwartz D, Brogi E, et al. A cascade model for restenosis. a special case of atherosclerosis progression. Circulation 1992;86:III47-52.

10 Faxon DP. Effect of high dose angiotensin-converting enzyme inhibition on restenosis: final results of the MERCATOR Study, a multicenter, double-blind, placebocontroled trial of cilazapril. The multicenter American research trial with cilazapril after angioplasty to prevent transluminal coronary obstruction and restenosis (MER-

11 Mento PF, Wilkes BM. Plasma angiotensins and blood pressure during converting enzyme inhibition. Hypertension 1987;9:III42-8

12 Aldigier JC, Huang H, Dalmay F, et al. Angiotensinconverting enzyme inhibition does not suppress plasma angiotensin II increase during exercise in humans. $f$ Cardiovasc Pharmacol 1993;21:289-95.

13 Miura S, Ideishi M, Sakai T, et al. Angiotensin II formation by an alternative pathway during exercise in humans. $f$ Hypertens 1994;12:1177-81.

14 Berk BC, Vekshtein V, Gordon HM, et al. Angiotensin II-stimulated protein synthesis in cultured vascular smooth muscle cells. Hypertension 1989;13:305-14.

15 Geisterfer AAT, Peach MJ, Owens GK. Angiotensin II induces hypertrophy, not hyperplasia, of cultured rat aortic smooth muscle cells. Circ Res 1988;62:749-56.

16 Daemen MJAP, Lombardi FT, Bosman FT, et al. Angiotensin II induces smooth muscle cell proliferation in the normal and injured rat arterial wall. Circ Res 1991;68:4506.

17 Laporte S, Escher E. Neointima formation after vascular injury is angiotensin II mediated. Biochem Biophys Res Commun 1992;187:1510-16.

18 Weber H, Webb ML, Serafino R, et al. Endothelin-1 and angiotensin II stimulate delayed mitogenesis in cultured rat aortic smooth muscle cells: evidence for common signaling mechanisms. Mol Endocrinol 1994;8:148-58.

19 Wolny A, Clozel JP, Rein J, et al. Functional and biochemi$\mathrm{cal}$ analysis of angiotensin II-forming pathways in the cal analysis of angiotensin II-forming
human heart. Circ Res 1997;80:219-27.

20 Okunishi H, Oka Y, Shiota N, et al. Marked speciesdifference in the vascular angiotensin II-forming pathways: humans versus rodents. Fpn f Pharmacol 1993;62:207-15.

21 Clozel JS, Hess P, Michael C, et al. Inhibition of converting enzyme and neointima formation after vascular injury in rabbits and guinea pigs. Hypertension 1991;18:II-55-9.

22 Shiota N, Okunishi H, Fukamizu A, et al. Activation of two angiotensin-generating systems in the balloon injured artery. FEBS Lett 1993;323:239-42. 